\title{
Skeletal Status Assessed by Quantitative Ultrasound in Elderly Women Compared with Early Postmenopausal Women
}

\author{
Bogna Drozdzowska ${ }^{*}, 1$, Wojciech Pluskiewicz ${ }^{2}$, Piotr Adamczyk ${ }^{3}$ and Waldemar Münzer ${ }^{4}$ \\ ${ }^{I}$ Department of Pathomorphology, Medical University of Silesia, Poland \\ ${ }^{2}$ Metabolic Bone Diseases Unit, Medical University of Silesia, Poland \\ ${ }^{3}$ Department and Clinic of Paediatric Diseases, Medical University of Silesia, Poland \\ ${ }^{4}$ Outpatient Medical Clinic, Dortmund, Germany
}

\begin{abstract}
Background: The aim of the retrospective study was to reveal the pattern of bone loss in elderly women compared with early postmenopausal women.

Material: The group of 254 women was studied, among them were 40 elderly women (mean age 74.7+/-4.0 y.) and 214 early postmenopausal women (mean age 53.4+/-3.7 y.). Skeletal status was evaluated using quantitative ultrasound (QUS) at the calcaneus (Achilles, Lunar, USA). Parameters measured were: Speed of Sound (SOS [m/s]), Broadband Ultrasound Attenuation (BUA [dB/MHz]) and Stiffness Index (SI [\%]).

Results: In elderly women age, years since menopause (YSM) and body size did not influence significantly ultrasound values, only positive influence of weight and body mass index on BUA was observed $(p<0.05)$. In early postmenopausal women YSM negatively affected $\operatorname{SOS}(p<0.05)$, BUA $(p=0.05)$ and $\mathrm{SI}(\mathrm{p}<0.05)$, body size had generally a positive impact on all QUS parameters, and the percentage of life with menstruation positively affected $\mathrm{SOS}(\mathrm{p}<0.05)$. In multiple stepwise regression analyses in elderly women only weight had a positive effect on BUA, and in early postmenopausal women, weight was a protective factor for all parameters, age negatively influenced BUA and SI, and YSM negatively influenced SOS. Multiple stepwise regression analysis in the whole group showed that weight was a protective factor and age was a negative factor for all QUS parameters.

Conclusion: The pattern of bone loss in the elderly differs in comparison to younger postmenopausal women, and the weight among factors assessed was the only protective one in postmenopausal women. Maintaince of body weight seems to be the most important in osteoporosis prevention.
\end{abstract}

Keywords: Quantitative ultrasound, elderly women, early postmenopausal women.

\section{INTRODUCTION}

Skeletal status and bone loss depends on several factors including mainly age, body size, function of endocrinological system, diet, physical activity, medications, smoking. However, in different age decades bone loss is under control of different factors. For example, in early postmenopausal women the main factor is diminished amount of estrogens and later in life the role of menopause decreases. Nordin et al. estimated that the majority of bone loss between 55 and 75 years was due to aging (62\%) rather than to menopause [1].

Bone loss leads to skeletal fragility and susceptibility for fractures. The most important are spine and hip fractures. The number of fractures increases with advancing age. Senile osteoporosis is one of the most important diseases in the elderly because its' health and economic impact. The knowledge which factors mainly affect skeletal status are essential for management of patients with osteoporosis. These informations are especially important in elderly subjects because

*Address correspondence to this author at the Department of Pathomorphology, Medical University of Silesia, 3 Maja 13/15 Street, 41-800 Zabrze, Poland; Tel: 48323704541; Fax: 48322714994;

E-mail: bognadr@poczta.onet.pl of multifactorial pathogenesis of the disease including also the risk of falls.

Currently, densitometric methods are the most commonly used in order to assess skeletal status in subjects with osteoporosis [2]. Last years were a period of the development of Dual Energy X-ray Absorptiometry (DXA) called a gold standard of densitometry. DXA widely used in a clinical practice does not provide any data on bone qualitative features. Obviously, both bone mineral density (BMD) and qualitative features of bone like elasticity or microarchitecture play a significant role in biologic competence of the skeleton. The role of bone quality is currently widely accepted and there is a need to develop new methods able to assess not only bone quantity.

Among techniques potentially expressing bone quality is quantitative ultrasound (QUS). QUS measurements were performed at several skeletal sites including calcaneus, radius, tibia and hand phalanges. QUS may give additional data on bone tissue qualitative features $[3,4]$ and in comparison with DXA has got some important advantages like the lack of ionizing radiation, relatively low costs and small sizes of equipment. QUS has also disadvantages involving difficulty in precise determination of measured bone tissue 
features, measurements of skeletal sites limited only to peripheral skeleton and relatively poor precision.

The assessment of fracture risk is the most important issue in osteoporotic patients. QUS measurements at calcaneus were performed in several case-control [4-16] and longitudinal studies [17-21]. In all of cited studies QUS measurements at the calcaneus were able to predict future osteoporotic fracture. Recently, in several studies the authors showed the utility of combing of clinical risk factors and heel bone ultrasound for fracture assessment [22-25].

In several studies were studied changes of calcaneal QUS parameters in respect to several factors like age, age at menopause or body size [26-38]. These data show the nature of bone changes over time and are important in patients' management.

The aim of the retrospective study was to reveal the pattern of bone loss in elderly women compared with early postmenopausal women.

\section{MATERIAL AND METHODOLOGY}

\section{Material}

The group of 254 patients recruired from Outpatient Osteoporotic Clinic was studied. The main inclusion criteria were female sex and postmenopausal status. Exclusion criteria included: surgical menopause, prior osteoporotic fracture, prior fractures of any origin within lower extremity in order to avoid their impact on the result of calcaneus measurements, the presence of medical reasons known to affect bone metabolism (either chronic diseases or prolonged medications), current or prior therapy for osteoporosis (hormonal replacement therapy, calcitonin, bisphosphonates, strontium ranelate, teriparatide, raloxifen), with the exception of preventive doses of vitamin D (200-400 IU daily) and calcium supplementation. We have used described exclusion criteria in order to follow nature of bone loss after menopause and in elderly subjects. We excluded 106 women; 67 due to therapy for osteoporosis, 20 because of secondary osteoporosis and 15 because of former osteoporotic fracture and four because of traumatic lower limb fracture. Clinical characteristics of women studied is given in Table $\mathbf{1}$.

\section{Methodology}

\section{Quantitative Ultrasound}

Skeletal status was evaluated using quantitative ultrasound (QUS) of calcaneus. QUS measurements at the dominant calcaneus were performed. The Speed of Sound - SOS $[\mathrm{m} / \mathrm{s}]$ and Broadband Ultrasound Attenuation - BUA $[\mathrm{dB} / \mathrm{MHz}]$ were measured with the Achilles system (Lunar, Madison, WI, USA). The Achilles software calculates a Stiffness Index (SI $[\%]=[0.67 x B U A+0.28 x$ SOS $]-420)$ which does not express biomechanical stiffness but rather is an attempt by the manufacturer to derive a clinically useful index combining BUA and SOS. T-score and Z-score were derived from the value of SI and expressed as a number of standard deviations (SDs) from the peak value and the mean value for age-matched population, respectively.

The device was calibrated daily in accordance with the manufacturer's recommendations. All measurements were made by the same operator. Precision was expressed using coefficient of variation (CV). They were calculated using following formulas: $\mathrm{CV} \%=(\mathrm{SD} / \mathrm{mean}) \times 100$. The $\mathrm{CV} \%$ values were: $3.8 \%$ for BUA, $0.45 \%$ for SOS, and $2.5 \%$ for SI.

Table 1. Clinical Characteristics of Women Studied (Mean +/-SD)

\begin{tabular}{|l|c|c|c|}
\hline & $\begin{array}{c}\text { Early } \\
\text { Postmenopausal } \\
\text { Women (n=214) }\end{array}$ & $\begin{array}{c}\text { Elderly } \\
\text { Women } \\
\text { (n=40) }\end{array}$ & p-Value \\
\hline \hline Age [Years] & $53.4+/-3.7$ & $74.7+/-4.0$ & $<0.000001$ \\
\hline Weight [kg] & $68.4+/-12.6$ & $72.4+/-13.4$ & $\mathrm{~ns}$ \\
\hline Height [cm] & $159.2+/-5.3$ & $156.9+/-5.11$ & $<0.05$ \\
\hline BMI [kg/m $\left.{ }^{2}\right]$ & $27.0+/-4.5$ & $29.4+/-5.4$ & $<0.01$ \\
\hline $\begin{array}{l}\text { Age at Menarche } \\
\text { [Years] }\end{array}$ & $13.8+/-1.6$ & $14.1+/-1.74$ & $\mathrm{~ns}$ \\
\hline $\begin{array}{l}\text { Age at Menopause } \\
\text { [Years] }\end{array}$ & $49.8+/-3.0$ & $49.95+/-4.7$ & $\mathrm{~ns}$ \\
\hline $\begin{array}{l}\text { Reproductive Period } \\
\text { [Menstrual Years] }\end{array}$ & $35.9+/-3.3$ & $35.85+/-4.2$ & $\mathrm{~ns}$ \\
\hline YSM & $3.7+/-2.6$ & $24.5+/-1.56$ & $<0.000001$ \\
\hline
\end{tabular}

BMI: body mass index. ns - not significant.

YSM: years since menopause.

\section{Statistics}

Statistical analysis was performed using Statistica for Windows. Descriptive statistics were presented as mean values and standard deviations (SDs). Statistics included:

- differences established using Student t-test,

- Pearson's correlation of ultrasound parameters with age, YSM, age at menopause and menarche, menstrual years, weight, height and BMI (body mass in$\left.\operatorname{dex}\left[\mathrm{kg} / \mathrm{m}^{2}\right]\right)$ in elderly women and in early postmenopausal women,

- $\quad$ multiple stepwise regression analyses of SOS, BUA and SI vs age, age at menopause, YSM, menstrual years, weight and height in elderly women, in early postmenopausal women and for the whole group.

Significance was achieved with $\mathrm{p}$ value lower than 0.05 .

\section{RESULTS}

The whole group of women studied was divided into:

elderly women $(n=40)$ - older than 60 years and about 25 years after menopause,

- $\quad$ early postmenopausal women $(n=214)$ - mean age about 53 years and up to ten years after menopause.

There were no differences between subgroups studied in age at menarche, age at menopause and in menstrual years (reproductive period). Clinical characteristics of women studied is given in Table $\mathbf{1}$.

Values of QUS parameters are shown in Table 2. As expected all QUS values were lower in elderly women. 
Table 2. Results of QUS Measurements (Mean +/- SD)

\begin{tabular}{|c|c|c|c|}
\hline Parameter & $\begin{array}{c}\text { Early } \\
\text { Postmenopausal } \\
\text { Women (n=214) }\end{array}$ & $\begin{array}{c}\text { Elderly } \\
\text { Women }(\mathbf{n}=\mathbf{4 0})\end{array}$ & p-Value \\
\hline \hline SOS [m/s] & $1520.2+/-27.0$ & $1504.5+/-53$ & $<0.001$ \\
Z-Score & $0.01+/-0.97$ & $0.21+/-1.08$ & $\mathrm{Ns}$ \\
\hline BUA [dB/MHz] & $108.9+/-10.5$ & $101.9+/-0.89$ & $<0.001$ \\
Z-Score & $-0.06+/-1.05$ & $0.21+/-1.02$ & $\mathrm{Ns}$ \\
\hline SI [\%] & $78.3+/-13.3$ & $69.2+/-13.5$ & $<0.0001$ \\
T-Score & $-1.97+/-1.21$ & $-2.77+/-1.22$ & $<0.001$ \\
Z-Score & $-0.32+/-1.2$ & $-0.08+/-1.23$ & $\mathrm{Ns}$ \\
\hline
\end{tabular}

SOS: Speed of Sound. Ns: not significant.

BUA: Broadband Ultrasound Attenuation.

SI: Stiffness Index.

T-score: number of SD from peak value.

Z-score: number of SD from age-matched value.

Table 3 presents correlation analyses of QUS parameters with others. In elderly women age, YSM, menstrual years, weight, height and BMI did not correlate significantly with QUS parameters, except for positive influence of weight and BMI on BUA $(p<0.05)$. In early postmenopausal women negative influence of YSM on SOS $(p<0.01)$, BUA $(p<0.05)$ and SI $(\mathrm{p}<0.05)$ was observed. Body size (weight, height, BMI) had a positive impact on all ultrasound parameters.

Table 4 presents results of multiple regression analyses. In elderly women only weight positively affected BUA $(\mathrm{p}<0.05)$. In early postmenopausal women, weight was a protective factor for all QUS parameters, age negatively influenced BUA and SI, and YSM affected negatively SOS $(p<0.0001)$. Multiple stepwise regression analysis for the whole group of women studied revealed that the weight was a protective factor and age was a negative factor for all ultrasound parameters.

In order to show the influence of age and YSM in the whole group two figures were created. Fig. (1) presents the association of age with SI which decreases with advancing age $(r=-0.27, p<0.001)$. Fig. (2) shows the association of YSM with SI which is weaker in elderly women $(r=-0.25$,

Table 3. Correlation Analysis in Women Studied

\begin{tabular}{|c|c|c|c|c|c|c|c|c|}
\hline Parameter & Age & Weight & Height & BMI & Menarche & Menstrual Years & Menopause & YSM \\
\hline \multicolumn{9}{|c|}{ - $\quad$ In Elderly Women $(n=40)$} \\
\hline BUA & -0.21 & $\begin{array}{c}0.38 \\
p<0.05\end{array}$ & -0.01 & $\begin{array}{c}0.38 \\
p<0.05\end{array}$ & -0.11 & -0.09 & -0.12 & -0.01 \\
\hline \multicolumn{9}{|c|}{ - In Early Postmenopausal Women (n=214) } \\
\hline SOS & -0.09 & $\begin{array}{c}0.28 \\
\mathbf{p}<0.001\end{array}$ & $\begin{array}{c}0.19 \\
p<0.01\end{array}$ & $\begin{array}{c}0.23 \\
p<0.01\end{array}$ & -0.07 & 0.05 & 0.012 & $\begin{array}{c}-0.15 \\
p<0.05\end{array}$ \\
\hline BUA & -0.08 & $\begin{array}{c}0.41 \\
p<0.001\end{array}$ & $\begin{array}{c}0.19 \\
p<0.01\end{array}$ & $\begin{array}{c}0.38 \\
\mathbf{p}<0.001\end{array}$ & -0.01 & 0.01 & 0.01 & $\begin{array}{c}-0.13 \\
p=0.05\end{array}$ \\
\hline
\end{tabular}

Table 4. Results of Multiple Regression Analysis in Women Studied

\begin{tabular}{|c|c|c|c|c|}
\hline Parameter & Equation & $\mathbf{R}^{2}$ & $\mathbf{p}$ & SEE \\
\hline \multicolumn{5}{|c|}{ - $\quad$ In Elderly Women $(n=40)$} \\
\hline BUA & BUA $(\mathrm{dB} / \mathrm{MHz})=79.9+0.37 \mathrm{x}$ weight $(\mathrm{kg})$ & 0.14 & $<0.05$ & 10.2 \\
\hline \multicolumn{5}{|c|}{ - In Early Postmenopausal Women (n=214) } \\
\hline SOS & $\operatorname{SOS}(\mathrm{m} / \mathrm{s})=1419+0.23 \times$ weight $(\mathrm{kg})-0.13 \times \mathrm{YSM}+0.09 \times$ height $(\mathrm{cm})$ & 0.1 & $<0.0001$ & 25.7 \\
\hline BUA & BUA $(\mathrm{dB} / \mathrm{MHz})=102.2+0.42 \times$ weight $(\mathrm{kg})-0.12 \mathrm{x}$ age $($ years $)$ & 0.18 & $<0.0001$ & 9.5 \\
\hline SI & SI $(\%)=76.1+0.39 \times$ weight $(\mathrm{kg})-0.14 \mathrm{x}$ age (years) & 0.16 & $<0.0001$ & 12.1 \\
\hline \multicolumn{5}{|c|}{ - In Whole Group $(n=254)$} \\
\hline SOS & $\operatorname{SOS}(\mathrm{m} / \mathrm{s})=1526+0.25 \mathrm{x}$ weight $(\mathrm{kg})-0.25 \mathrm{x}$ age (years) & 0.34 & $<0.000001$ & 26.3 \\
\hline BUA & BUA $(\mathrm{dB} / \mathrm{MHz})=105+0.39 \mathrm{x}$ weight $(\mathrm{kg})-0.29 \mathrm{x}$ age $($ years $)$ & 0.47 & $<0.000001$ & 9.6 \\
\hline SI & $\mathrm{SI}=77.8+0.35 \mathrm{x}$ weight $(\mathrm{kg})--0.30 \mathrm{x}$ age $($ years $)$ & 0.44 & $<0.000001$ & 12.4 \\
\hline
\end{tabular}


$\mathrm{p}<0.001$ ). Fig. (3) shows the association of weight with SI ( $\mathrm{r}$ $=+0.32, \mathrm{p}<0.001)$.

\section{DISCUSSION}

In the study were shown distinct differences in skeletal changes in elderly $v s$ early postmenopausal women. In eld- erly, the risk of osteoporotic fracture is modified by two main factors: skeletal status and number of falls. In current study we attempt to reveal which factors are responsible for bone loss and the analysis gave also an opportunity to show protective factors. The pattern of bone loss differs in regard to early postmenopausal women; age had only weak, nonsignificant negative influence and YSM did not affected

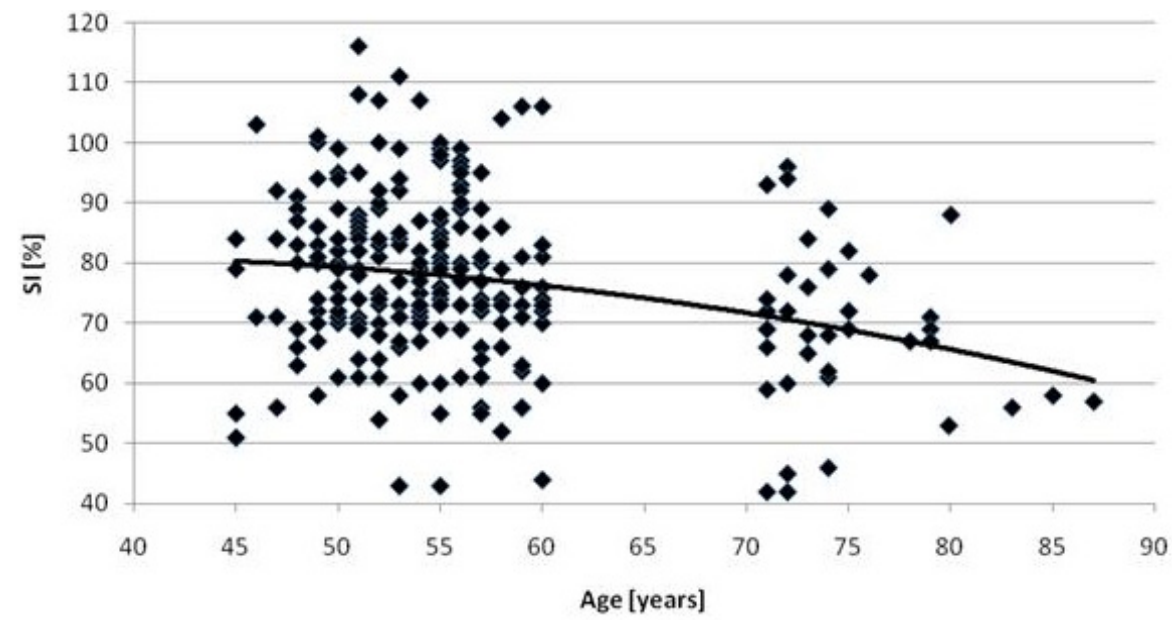

Fig. (1). The correlation of age with SI in the whole group.

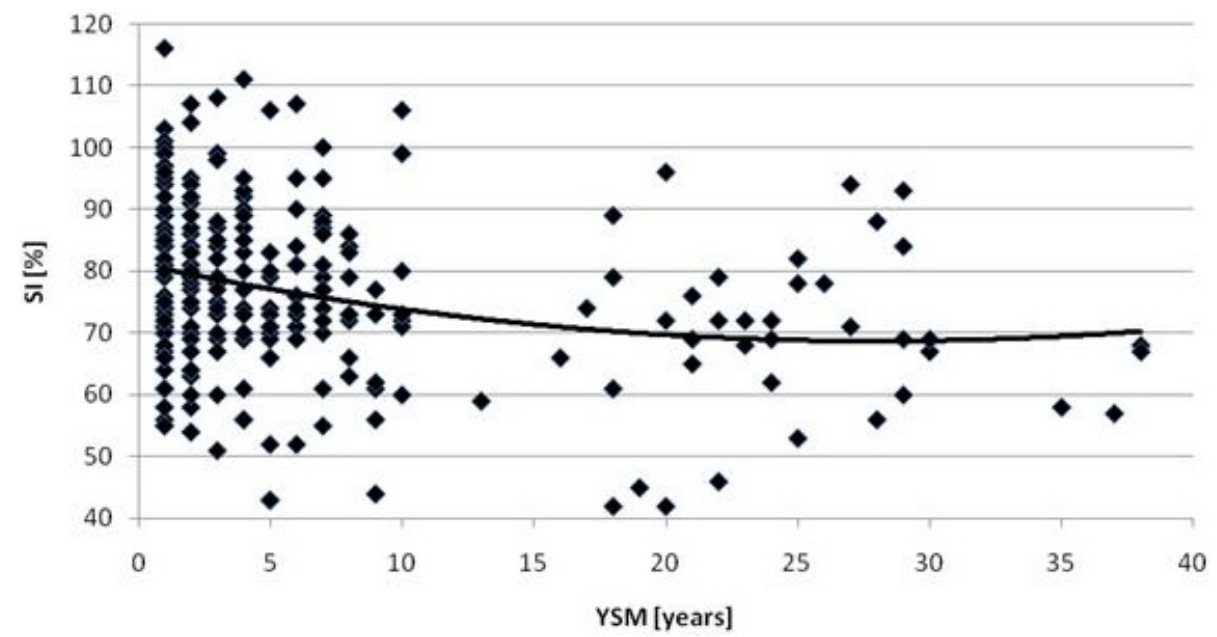

Fig. (2). The correlation of YSM with SI in the whole group.

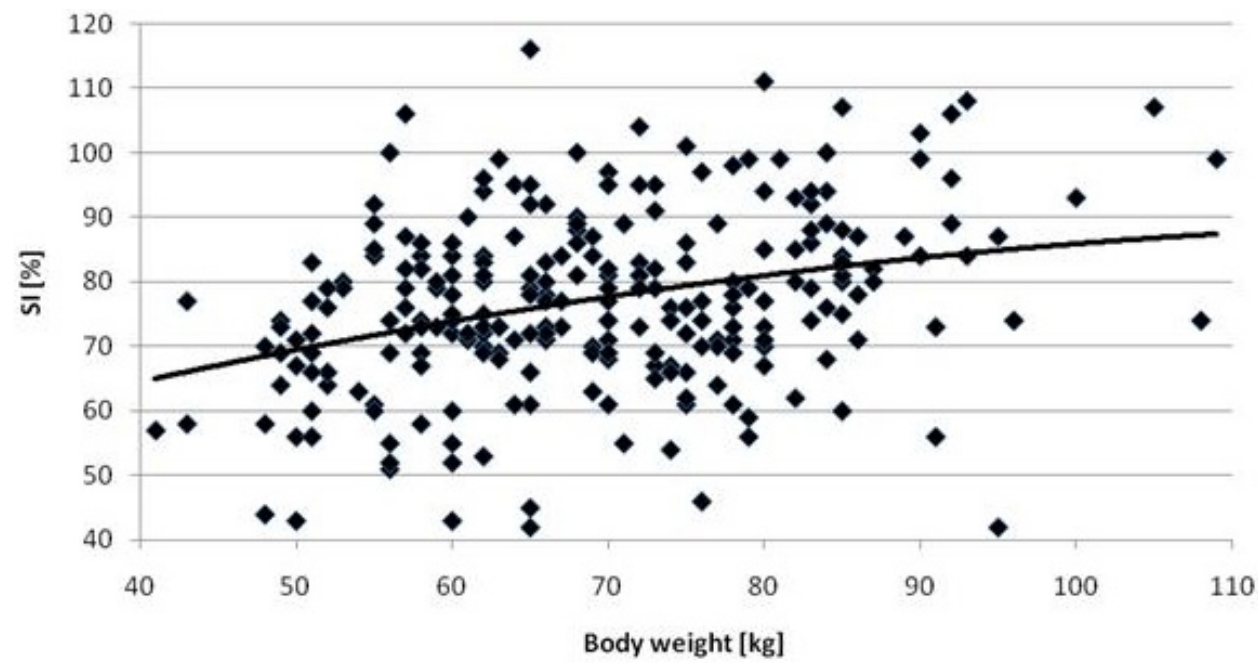

Fig. (3). The correlation of body weight with SI in the whole group. 
QUS parameters. In early postmenopausal women age had also only negative, non-significant influence, and the main factor were YSM. These relationships are clearly shown in Figs. $(1,2)$.

Some differences are also shown by correlation analysis; in younger group weight, height and BMI were protective for all QUS parameters, while in elderly weight and BMI had a positive influence only for BUA. An interesting view provides multiple regression analysis; in elderly only weight had a positive influence (for BUA), and in early postmenopausal women relatively strong protective factor was weight and negative factors were age (for BUA and SI) and YSM (for SOS). However, in the same multiple regression analysis performed in the whole group the only bone protector was weight and factor causing bone loss was age.

We consider that the most important clinical finding of the study is observation that weight is an important factor in elderly women in protecting from bone loss.

In some yet published studies [26, 29, 32, 33, 35, 37], calcaneus was assessed by QUS measurements, and the authors evaluated factors affecting skeletal status. In French study [26] both age and YSM affected QUS parameters, but after the age of 60 further bone loss was not observed. Also in the Rotterdam Study [29], age affected SOS and BUA in women, and BMI was a strong protector for both parameters. Age at menopause did not affect QUS parameters and the influence of other parameters like YSM, years of menstruation or age of menarche were not presented. In a group of 712 Polish women aged 52-74 years the main negative factor was age and weight was a protector [32]. In a study conducted in 1333 German women were presented exact values of QUS variables but correlation analysis was not shown [33]. In other study age and BMI [35] affected QUS parameters in postmenopusal women over 50, and further author showed that more than 5 YSM negatively affected QUS parameters [37].

In studies cited above several factors were assessed but the comparison of early postmenopausal women with elderly were not done. In curent study we have proven that the pattern of bone loss expressed by QUS mesurements differs in elderly women in comparison to early postmenopausal women. Therefore, further direct comparisons are not possible.

In several studies the influence of different factors on bone densitometry measurements were performed [27, 28, $30,31,34,36,38]$. In the study of 555 women aged 60 to 89 years age at menopause and number of reproductive years had positive associations with bone mineral density of radius, hip and spine, and total number of reproductive years explained more of variance in BMD than did either age at menarche or age at menopause [27]. In our study we did not note an influence of menstrual years on QUS parameters, but in early postmenopausal women menstrual years in regard to lifetime significantly improved value of SOS. In elderly women even a negative, non-significant associations of reproductive years was observed. In a great group studied $(\mathrm{n}=2230)$ by Fox et al. [28] aged 65 years or more, radial BMD increases with lower age of menarche, and each decade of menstruation caused an increase in BMD of $2 \%$. In a group of 1521 Finnish women protective factors against low
BMD was weight, and in multiple regression analysis YSM, age, age at menarche negatively and weight positively affected BMD [30]. Japanese postmenopausal women who had a late menopause and more reproductive years were at decreased risk for low BMD [31]. In a group of early postmenopausal women aged 45-61 years low age at menarche improved spine BMD, years of menstruation were positively associated with BMD of spine, hip, radius and total body, and YSM was constant negative factor [34]. In the same study in multiple regression analysis years of menstruation, hysterectomy status and duration of hormone replacement therpay use were found to have strong associations with BMD at all sites. YSM were not a significant factor. However, in regression analysis body size and age were not taken into consideration.

Interesting data provides a study by Gerdhem and Obrant [36]. A large group of 1044 women aged 75 years was studied. Age at menarche or menopause as well as length of fertile period did not affect spine or femoral neck BMD. These results are in consistency with our results. In a recent study [38] performed in a group of 2769 postmenopausal women the main factor were YSM followed by age at menopause.

Our study has some limitations: a group studied, especially elderly women was small and we did not use bone densitometry. In current retrospective study we were not able to assess some other factors potentially influencing bone status like physical activity, diet, bone turnover.

\section{CONCLUDING REMARKS}

The pattern of bone loss in elderly differs in comparison to younger women, and weight among factors assessed was the only protective factor. Maintaince of body weight seems to be the most important in osteoporosis prevention.

\section{REFERENCES}

[1] Nordin BEC, Need AG, Bridges A, Horowitz A. Relative contribution of age and years since menopause to postmenopausal bone loss. J Clin Endocrinol Metab 1990; 70: 83-8.

[2] Gluer C, Wu CY, Genant HK. Broadband attenuation signals depend on trabecular orientation: an in vitro study. Osteoporos Int 1993; 3: 185-91.

[3] Cavani F, Fini M, de Terlizzi F, et al. Effect of trabecular orientation on mechanical resistance and ultrasound propagation in specimens of equine vertebrae. Ultrasound Med Biol 2003; 29: 1777-85.

[4] Baran DT, Kelly AM, Karellas A, et al. Ultrasound attenuation of the os calcis in women with osteoporosis and hip fractures. Calcif Tissue Int 1988; 43: 138-42.

[5] Cepollaro C, Gonnelli S, Pondrelli C, et al. The combined use of ultrasound and densitometry in the prediction of vertebral fracture. Br J Radiol 1997; 70: 691-6.

[6] Schott AM, Weill-Engerer S, Hans D, et al. Ultrasound discriminates patients with hip fracture equally well as dual energy X-ray densitometry and independently of bone mineral density. J Bone Miner Res 1995; 10: 243-9.

[7] Donaldson MMK, McGrother CW, Clayton DG, Clarke M, Osborne D. Calcaneal ultrasound attenuation in an elderly population: measurement position and relationships with body size and past fractures. Osteoporos Int 1999; 10: 316-24.

[8] Drozdzowska B, Pluskiewicz W. Quantitative ultrasound at the calcaneus in premenopausal women and their postmenopausal mothers. Bone 2001; 29(1): 79-83.

[9] Drozdzowska B, Pluskiewicz W. The ability of quantitative ultrasound at the calcaneus to identify postmenopausal women with different types of non-traumatic fractures. Ultrasound Med Biol 2002; 28: $1491-7$. 
[10] Pluskiewicz W, Drozdzowska B. Ultrasonic measurement of the calcaneus in Polish normal and osteoporotic women and men. Bone 1999; 24: 611-7.

[11] Frost ML, Blake GM, Fogelman I. Contact quantitative ultrasound: an evaluation of precision, fracture discrimination, age-related bone loss and applicability of the WHO criteria. Osteoporos Int 1999; 10: 441-9.

[12] Frost ML, Blake GM, Fogelman I. A comparison of fracture discrimination using calcaneal quantitative ultrasound and dual $\mathrm{X}$ ray absorptiometry in women with a history of fracture at sites other than the spine and hip. Calcif Tissue Int 2002; 71: 207-11.

[13] Gluer CC, Eastell R, Reid DM, et al. Association of five quantitative ultrasound devices and bone densitometry with osteoporotic vertebral fractures in a population-based sample: the OPUS study. J Bone Miner Res 2004; 19: 782-93.

[14] Hadji P, Hars O, Wuster Ch, et al. Stiffness index identifies patients with osteoporotic fractures better than ultrasound velocity or attenuation alone. Maturitas 1999; 31: 221-6.

[15] Hadji P, Hars O, Gorke K, Emons G, Schulz KD. Quantitative ultrasound of os calcis in postmenopausal women with spine and hip fractures. J Clin Densitom 2000; 3: 233-9.

[16] Maggi S, Noale M, Giannini S, et al. Quantitative heel ultrasound in a population-based study in Italy and its relationship with fracture history: ESOPO study. Osteoporos Int 2006; 17: 237-44.

[17] Porter RW, Miller CG, Grainger D, Palmer SB. Prediction of hip fracture in elderly women: a prospective study. BMJ 1990; 29: 638-41.

[18] Bauer DC, Gluer CC, Cauley JA, et al. Broadband ultrasound attenuation predicts fractures strongly and independently of densitometry in older women: A prospective study. Study of Osteoporotic Fractures Research Group. Arch Int Med 1997; 157: 62934.

[19] Hans D, Dargent-Molina P, Schott AM, et al. Ultrasonographic heel measurements to predict hip fracture in elderly women: the EPIDOS prospective study. Lancet 1996; 348: 511-4

[20] Huopio J, Kroger H, Honkanen R, Jurvelin J, Saarikoski S, Alhava E. Calcaneal ultrasound predicts early postmenopausal fractures as well as axial BMD. A prospective study of 422 women. Osteoporos Int 2004; 15: 190-5.

[21] Pluijm SMF, Graafmans WC, Bouter LM, et al. Ultrasound measurements for the prediction of osteoporotic fractures in elderly people. Osteoporos Int 1999; 9: 550-6.

[22] Durosier C, Hans D, Krieg MA, et al. Combining clinical factors and quantitative ultrasound improves the detection of women both at low and high risk for hip fracture. Osteoporos Int 2007; 18: 1651-9.

[23] Hans D, Durosier C, Kanis JA, Johannson H, Schott-Pethalaz AM, Krieg MA. Assessment of the 10-year probability of osteoporotic hip fracture combining clinical risk factors and heel bone ultrasound: the EPISEM prospective cohort of 12,958 elderly women. J Bone Min Res 2008; 23: 1045-51.
[24] Guessous I, Cornuz J, Ruffieux C, Burckhardt P, Krieg MA. Osteoporotic fracture risk in elderly women: estimation with quantitative heel US and clinical risk factors. Radiology 2008; 248: 179-84.

[25] Diez-Perez A, Gonzalez-Macias J, Marin F, et al. Prediction of absolute risk of non-spinal fractures using clinical risk factors and heel quantitative ultrasound. Osteoporos Int 2007; 18: 629-39.

[26] Schott AM, Hans D, Sornay-Rendu E, Delmas PD, Meunier PJ. Ultrasound measurements on os calcis: precision and age-related changes in a normal female population. Osteoporos Int 1993; 3 . 249-54

[27] Kritz-Silversten D, Barett-Connor E. Early menopause, number of reproductive years, and bone mineral density in postmenopausal women. Am J Public Health 1993; 83: 983-8.

[28] Fox KM, Magaziner J, Sherwin R, et al. Reproductive correlates of bone mass in elderly women. Study of Osteoporotic Research Group. J Bone Miner Res 1993; 8: 901-8.

[29] Van Daele PLA, Burger H, Algra D, et al. Age-associated in ultrasound measurements of the calcaneus in men and women: the Rotterdam Study. J Bone Miner Res 1994; 9: 1751-7.

[30] Tuppurainen M, Kroger H, Saarikoski S, Honkanen R, Alhava E. The effect of gynecological risk factors on lumbar and femoral bone mineral density in peri- and postmenopausal women. Maturitas 1995; $21: 137-45$

[31] Osei-Hyiaman D, Satoshi T, Ueji M, Hideto T, Kano K. Timing of menopause, reproductive years, and bone mineral density: a crosssectional study of postmenopausal Japanese women. Am J Epidemiol 1998; 148: 1056-61.

[32] Pluskiewicz W. Bone status assessed by quantitative ultrasound in healthy postmenopausal Polish women: a normative data. Clin Rheumatol 1998; 17: 40-3.

[33] Hadji P, Hars O, Bock K, et al. Age changes of calcaneal ultrasonometry in healthy German women. Calcif Tissue Int 1999 65: 117-20

[34] Grainge MJ, Coupland CA, Cliffe SJ, Chilvers CE, Hosking DJ. Reproductive, menstrual amd menopausal factors: which are associated with bone mineral density in early postmenopausal women? Osteoporos Int 2001; 12: 777-87.

[35] Saadi HF, Reed RL, Carter AO, Dunn EV, Qazaq HS, Al.-Suhaili AR. Quantitative ultrasound of the calcaneus in Arabian women: relation to anthropometric and lifestyle factors. Maturitas 2003; 28 215-23.

[36] Gerdham P, Obrant KJ. Bone mineral density in old age: the influence of age at menarche and menopause. J Bone Miner Metab 2004; 22: 372-5

[37] Gemalmaz A, Discigil G, Sewnsoy N, Basak O. Identifying osteoporosis in a primary care setting with quantitative ultrasound: relationship to anthropometric and lifestyle factors. J Bone Miner Metab 2007; 25: 184-92.

[38] Demir B, Haberal A, Geyik P, et al. Identification of the risk factors for osteoporosis among postmenopausal women. Maturitas 2008; 60: 253-6. 